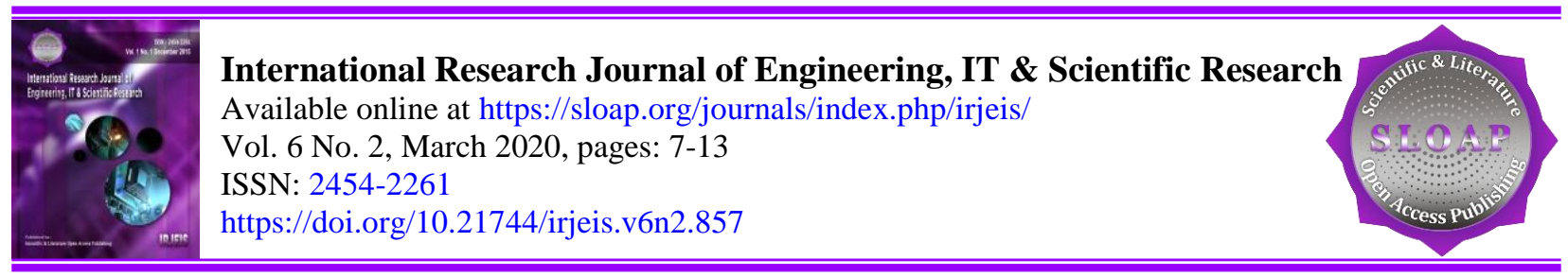

\title{
Educational Strategy to Favor the Satisfaction of Basic Psychological Needs in Young People of Yogic Group Studies Al Ananda De Guantanamo
}

\author{
Nayra Martínez Manzanares a \\ José Ignacio Ruiz Sánchez ${ }^{\text {b }}$ \\ Hilda Rosa Rabileros Sabatés ${ }^{c}$ \\ Meglis Rivero Favier ${ }^{d}$
}

Article history:

Submitted: 18 November 2019

Revised: 27 December 2019

Accepted: 31 January 2020

\section{Keywords:}

basic psychological needs; educational strategy;

fish welfare;

physical activity;

self-determination;

\begin{abstract}
Accordingly, with analyzes made earlier in this article, the theoretical foundation of an educational strategy that provides the Al Ananda Yogic Studies Group of the Guantánamo province is presented, with the necessary tools to contribute to the satisfaction of basic psychological needs, from the Systemic work with the group members, specialists in Physical Culture and yoga monitors, based on the barriers and potential identified in the group's diagnosis. A theoretical-practical and methodological reference structure is provided, so that the process of socialization and interaction in the group can be intended on satisfactory elements that require direct treatment, as a foundation for more complex formations such as intrinsic behaviors that enable psychological well-being, the motivation seen as the existence of an accumulation of energy generated by different human needs that will subsequently acquire a direction or orientation towards the satisfaction of those needs.
\end{abstract}

International research journal of engineering, IT \& scientific research () 2020. This is an open access article under the CC BY-NC-ND license (https://creativecommons.org/licenses/by-nc-nd/4.0/).

\section{Corresponding author:}

Nayra Martínez Manzanares,

Universidad de Guantánamo, Guantánamo, Cuba.

Email address: nayra88@nauta.cu

\footnotetext{
${ }^{a}$ Universidad de Guantánamo, Guantánamo, Cuba

${ }^{\mathrm{b}}$ Universidad de Camagüey, Camaguey, Cuba

${ }^{c}$ Universidad de Oriente, Santiago de Cuba, Cuba

${ }^{\mathrm{d}}$ Universidad de Guantánamo, Guantánamo, Cuba
} 


\section{Introduction}

It is considered that participation in physical activities, specifically the practice of yoga provides significant benefits for physical, psychological and social health and is recommended as a strategy to promote health to the population. However, his practice in Cuba is still limited by the little culture and beliefs associated with this practice; Well, the tendency of the population is to practice aerobics either in gyms or outdoors.

Within the different dimensions of physical activity (utilitarian, educational, recreational, competitive, health, etc.), the search for physical and emotional well-being by the practitioner is notable. Exercising physically, enjoying and living comforting, satisfying and stimulating experiences are the main reasons for physical and sports practice alluded to by the population (García Ferrando, 2006). In this sense, one of the theories that best explain and helps to understand the motivation and the different processes that surround it is the theory of self-determination (Deci \& Ryan, 1985, 1991, 2000). This theory considers that all human behavior has motivated by three primary and universal psychological needs: autonomy, competence and relationship with others, which seem to be essential to facilitate optimal functioning, psychological growth, social development and personal well-being (Deci \& Ryan, 2000; Ryan \& Deci, 2000).

To achieve this psychological well-being, an educational strategy has proposed that enables the satisfaction of these needs in the context of the practice of yoga; for which this article will theoretically base said Educational Strategy; which will lead the practitioner to experience intrinsic motivational states, characterized by the search for enjoyment during practice.

\section{Materials and Methods}

\section{Development}

The term Strategy is a word that comes from the Greek "strategia" (boss) or "strategists", which means "general. It is considered a mediating force or of "coupling" between an organization and the environment (internal and external context). It has different meanings depending on the extent to which it refers. It is defined from different authors as Ruiz (2001); Rodríguez Del Castillo \& Rodríguez Palacios (2005); Suarez \& Sabatés (2020); De Armas, N. González \& Perdomo (2011), cited by. Vega (2008). The following regularities are determined from the considerations of these authors:

a) It was designed to respond to a contradiction. between the current and desired state of an object or specific phenomenon located in space and time that is solved by the programmed use of certain resources and means.

b) Conception from a systemic approach in which coordination relationships predominate, although relations of subordination and dependence are still present.

c) It has a dialectical character that is given by the search for the qualitative change that will occur in the object (real state to desired state), for the constant adaptations and readjustments that its actions can undergo and for the articulation between the objectives (goals pursued) and the methodology (instrumented ways to achieve them), among others.

d) Structuring from phases or stages where the process of planning, organization, and control of actions (more or less complex) with a coherent, conscious, intentional integrated, systemic, transformative and flexible character.

e) The determination of goals and objectives in the long, medium and short term, aimed at solving the problem based on the progressive achievement of these goals.

f) It involves an adaptation of necessary actions and resources that adjust to the changes that occur.

g) Adoption of a specific typology, which has conditioned by the element that becomes the object of transformation this last category, has essential for selecting which variant to use within the existing taxonomy.

h) Its unrepeatability: the strategies are casuistic and valid in their entirety in a moment and context-specific, therefore its universe of application is smaller than that of other scientific results. This does not contradict the fact that one or more of its actions has be repeated in other areas.

i) Your eminently practical contribution, due to its representative level of tangibility and utility. It does not deny the existence of theoretical and methodological contributions within its conformation. 
In the structuring of any strategy, it is required to define stages that will organize the entire process. Its delimitation has dissimilar terminologies. At the author's discretion, Arredondo (1981); Molina (1989); Paramita et al. (2018); Añorga (1995); Matos Columbié (2003); cited by Daudinot (2013), figure 1 shows the stages, which are assumed in this research:

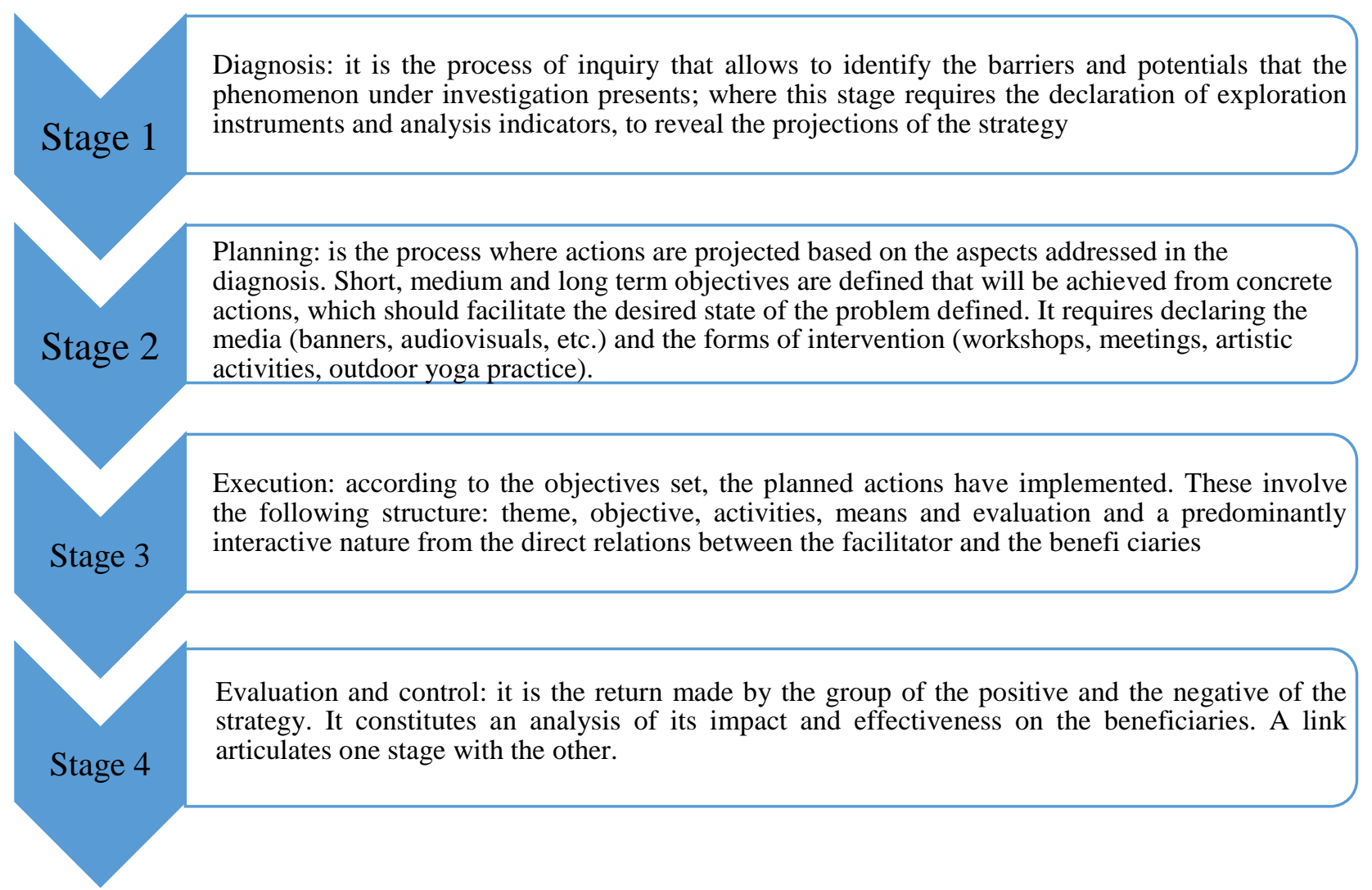

Figure 1. Stages of research

\section{Results and Discussions}

Strategies in educational processes have developed from the following levels:

a) Macro (social, institutional): where the general guidelines have declared for compliance with a certain general policy.

b) Group: the activities have specified in a specific group or group of individuals.

c) Individual: where the tasks, responsibilities have defined and the participation of each individual, their mechanisms and methods to reach the predetermined goal are defined operationally.

According to the specificity of the object of transformation in this research, the proposed strategy has classified as educational. According to Rodríguez del Castillo (2004): the projection of a system of actions to short, medium and long term that allows the transformation of the modes of action of its beneficiaries to achieve in a specific time the objectives committed to the formation, development, and improvement of moral and intellectual faculties.

In accordance with the above, the author defines it as the dynamic, operational and socio-educational process to favor the psychosocial growth of the members of the pedagogical process, taking as a starting point the real social development situation to carry out systematic and contextualized development actions.

From the structuring of the educational strategy, actions are concretized in the group taking into account the moments and spaces of encounter, in interaction with the family and community context, all of which create an unrepeatable didactic environment. If you want to achieve people capable of self-determination, of voluntarily

Manzanares, N. M., Sánchez, J. I. R., Sabatés, H. R. R., \& Favier, M. R. (2020). Educational strategy to favor the satisfaction of basic psychological needs in young people of yogic group studies Al Ananda De Guantanamo. International Research Journal of Engineering, IT \& Scientific Research, 6(2), 7-13. https://doi.org/10.21744/irjeis.v6n2.857 
directing the behavior through increasingly internal forces, active beings with a tendency to develop, grow, seek, and integrate the perceived experience, both at the level of external and internal elements. It is necessary to stop to think about how to stop treating these aspects from chance and spontaneity and assume another alternative that favors it in a systematic and effective way.

This research proposal has intended to increase the level of preparation of yoga monitors, family and community agents in the short term, in the medium term it will allow a reduction of a state of lack and thus achieve the satisfaction of these needs. In the long term, it facilitates moving towards a society constituted by people capable of considering themselves as beings capable of influencing behavior in their own life or reality, feeling free to choose, the feeling of being skilled and feeling part of a group, with which to interact in a positive way and establishing mutually supportive relationships.

It has declared as a theoretical platform to structure the educational strategy, the dialectical-materialist conception from the historical-cultural approach, of LS Vigotsky, which provides a group of categories that allow the understanding and explanation of self-determination as well as the design of the proposal. The following have assumed:

a) The conception of personality: its configuration from inter and intrapsychic elements (self-esteem, attitudes, affections, knowledge, abilities to satisfy the needs).

b) The dialectical unit between activity and communication: the structuring of character activities has conceived individuals and groups to develop skills promoted at the interpsychic level from communication, and then internalized in the subject.

c) Mediation is as used as a psychoeducational and socializing tool for knowledge and attitudes, which are enhanced through the interrelationships between the strategy facilitators and their beneficiaries.

From this complex interaction of the individual with the world and objects, through the recognition of their actions and transforming role in their personal construction, the process of appropriation of culture occurs. In order to articulate these elements in the educational strategy in a coherent way, according to the peculiarities of the specific context, their human relationships, habits and social representations as experiential support for the satisfaction of basic psychological needs. It is necessary to rely on the Systems Approach, based on the conception of authors such as Von Bertalanffy (1968). From her theoretical assessments, the author identifies with the latter's criteria which define the system approach as a scientific method of analysis whose essence lies in conceiving each problem, process or event of reality as an integrated whole, taking into account all the interrelationships between its components and the system and its environment.

From these considerations, the following have declared as basic principles in this approach:

a) The phenomenon or process understood as a global whole or unit, and at the same time as a composition of diverse and interconnected parts.

b) The relative role of each of the subsystems within the more general system.

c) System properties and their positive or negative interrelationships develop internally and at the same time during their relationship with the environment.

d) It presents laws that regulate its operation.

e) The balance between the system and the environment makes it possible to solve a specific problem.

In the educational strategy, the above translates into the assessment of self-determination as a system and its subsystems to the different socializing agents and their beneficiaries. Each according to their functions, interrelations, knowledge, and characteristics to solve a problem or social need in their context: the satisfaction of basic psychological needs in young people of the Al Ananda Group. This allows, from the strategy, the modes of action of each of its parts are redefined and transformed.

In turn, the contribution of the thesis responds to the Social Policy regarding sport, which is included in the guidelines of the Communist Party of Cuba; the following stand out:

116. Promote the integral and full development of human beings. Continue to consolidate the conquests of the Revolution, such as access to medical care, education, culture, sports, recreation, justice, citizen tranquility, social security and protection through social assistance to people who need it. Promote and reaffirm the adoption of the values, practices and attitudes that must distinguish our society.

134. Prioritize the integral improvement of the Cuban sports system, tempered to both national and international conditions. Continue to promote the development of physical culture and achieve the massive practice of sport that 
contributes to raising the quality of life of the population, having the school as a fundamental link. Maintain satisfactory results in international events.

All this confirms the need and integration in the attention to the individual needs of the members of the group and distinguishes this space as a socializing agent of greater prominence by the organicity, planning, involvement, ways of integration and openness in the process of development of the individual. In this sense, the proposed strategy constitutes a contextualized contribution to strengthen the personnel that it directs, to improve the quality and effectiveness of the process.

In turn, Addine (2002); Recarey (2003), propose a set of pedagogical principles, which need to be reviewed as they dialectically integrate the elements on which the educational strategy is based. In this order, they are declared:

a) Principle of the unity of scientific and ideological character in the process of personality education. Every educational process must have based on knowledge and ways that are consistent with the Ideological conception of Cuban society, which requires the education of highly committed subjects, capable of adequately coping with changes, contingencies and giving them a solution.

b) Principle of linking education with life and the social environment. The strategy empowers through examples or analysis of cases that generate reflection or awareness about how what is learned is useful for life, emphasizing the satisfaction of Basic Psychological Needs (NPB).

c) Principle of the unity of the instructive, the educational and the developer. Any action or activity to the satisfaction of the NPB must contain these three aspects, implying in this very all the beneficiaries of the educational strategy. This dynamic stimulates the gradual development of their potential.

d) Principle of the unity of the affective and the cognitive. This binomial constitutes the center of regulation of the conduct. Based on this, its overlapping has considered in the educational contents that will be worked on in the strategy, being relevant to the contextualization of the situations addressed and the personalized analysis of the aspects that hinder the satisfaction of the NPB of the group members. So that the participants commit themselves to this task, motivate themselves, be creative and thus promote positive changes in their convictions, as an expression of their personological self-regulation from the experience.

e) Principle of the collective and individual nature of education and respect for personality. Although the strategy is designed for group work, taking into account aspects in common, it is necessary to respect the particularities of each member, assuming personalized attention in the activities as required, as well as taking advantage of individual qualities as a dynamic, remedial or developer aspect to promote changes in the other members of the group.

Principle of unity between activity, communication, and personality. Your joint acts as a driving force to generate changes and subjective restructuring, being the basis on which education for the satisfaction of the NPB has erected once the aspects addressed by strategy have internalized.

\section{Conclusion}

The foundation of the educational strategy was based on the conceptual theoretical assumptions of the historicalcultural conception, of LS Vigotsky and Berthalanfy's systemic approach. This allows structuring an educational strategy whose stages and actions have a system character from relationships and existing links to favor the satisfaction of basic psychological needs in young people from the An Ango Yogic Studies group of Guantanamo.

\section{Conflict of interest statement}

The authors declared that they have no competing interests.

\section{Statement of authorship}

The authors have a responsibility for the conception and design of the study. The authors have approved the final article.

\section{Acknowledgments}

We are grateful to two anonymous reviewers for their valuable comments on the earlier version of this paper.

Manzanares, N. M., Sánchez, J. I. R., Sabatés, H. R. R., \& Favier, M. R. (2020). Educational strategy to favor the satisfaction of basic psychological needs in young people of yogic group studies Al Ananda De Guantanamo. International Research Journal of Engineering, IT \& Scientific Research, 6(2), 7-13. https://doi.org/10.21744/irjeis.v6n2.857 


\section{References}

Addine, F. F. (2002). Principles for the direction of the pedagogical process. p: 80-97. In Compendium of Pedagogy. Havana, Editorial People and Education.

Añorga, J. (1995). Advanced Education: a theory for professional and human improvement. advanced education newsletter, 1 (1).

Arredondo-Dowd, P. M. (1981). Personal loss and grief as a result of immigration. Personnel \& Guidance Journal.

Borges de Araujo, F.E. (2018). The satisfaction of basic psychological needs towards exercise (SNPBE) in childhood as an indicator of SNPBE in adulthood. Doctoral thesis presented as a requirement for the completion of the PhD program in Physical Activity, Physical Education and Sports, of the Faculty of Education of the University of Barcelona. Spain.

Castillo, R. D., \& Rodríguez Palacios, A. (2005). La estrategia como resultado científico de la investigación educativa. Centro de Investigaciones Pedagógicas Féliz Varela.

Daudinot, G.J. (2013). The pedagogical professional reaffirmation from work with the family at the University of Pedagogical Sciences. Thesis presented as an option to the Scientific Degree of Doctor of Pedagogical Sciences. Guantanamo

De Armas Ramírez, N., Lorences González, J., \& Perdomo Vázquez, J. M. (2011). Caracterización y diseño de los resultados científicos como aportes a la investigación educativa.[monografía en internet].

Deci, E. L., \& Ryan, R. M. (1985). Self-determination and intrinsic motivation in human behavior. EL Deci, RM Ryan. -1985 .

Deci, E. L., \& Ryan, R. M. (1991). A motivational approach to self: Integration in personality.

Deci, E. L., \& Ryan, R. M. (2000). The" what" and" why" of goal pursuits: Human needs and the self-determination of behavior. Psychological inquiry, 11(4), 227-268. https://doi.org/10.1207/S15327965PLI1104_01

García Ferrando, M. (2006). Postmodernity and sport: between individualization and massification. Survey of Spanish sports habits 2005.

Matos Columbié, Z. (2003). Vocational guidance Pedagogical model for its development in pre-university (Doctoral dissertation, Thesis presented as an option to the Scientific Degree of Doctor of Pedagogical Sciences. ISPEJV. Havana).

Molina-Sabio, M., \& Torregrosa, R. (1989). The combined use of different approaches in the characterization of microporous carbons. Carbon, 27(1), 23-32.

Paramita, D. P., Adiatmika, I., Kuswardhani, T., \& Mustika, I. W. (2018). Physiological and psychosocial change and the need of health intervention model for elderly. International Journal of Health Sciences, 2(2), 61-67. https://doi.org/10.29332/ijhs.v2n2.160

Recarey, S. (2003). Selección de lecturas y técnicas para el taller de orientación educativa y rol profesional. Ciudad de la Habana: Editorial Pueblo y Educación.

Rodríguez del Castillo, MA (2004). Approaches to the study of strategies as a scientific result. Center of Pedagogical Sciences and Research of the Félix Varela Pedagogical University.

Ruiz-Ortega, M., Lorenzo, O., Ruperez, M., Esteban, V., Suzuki, Y., Mezzano, S., ... \& Egido, J. (2001). Role of the renin-angiotensin system in vascular diseases: expanding the field. Hypertension, 38(6), 1382-1387. https://doi.org/10.1161/hy1201.100589

Ryan, R. M., \& Deci, E. L. (2000). Intrinsic and extrinsic motivations: Classic definitions and new directions. Contemporary educational psychology, 25(1), 54-67. https://doi.org/10.1006/ceps.1999.1020

Suarez, M. C. G., \& Sabatés, H. R. R. (2020). Alternative psychological improvement for karate-do trainers from Santiago de Cuba. International Research Journal of Engineering, IT \& Scientific Research,6(1), 11-17. https://doi.org/10.21744/irjeis.v6n1.847

Vega, G.D. (2008). Pedagogical strategy for the education of sexuality from a gender perspective in the initial training process of the preschool educator and educator. Thesis presented in option to the scientific degree of Doctor of Pedagogical Sciences. Las Tunas

Von Bertalanffy, L. (1968). General system theory: Foundations. Development, applications, 3. 


\section{Biography of Authors}

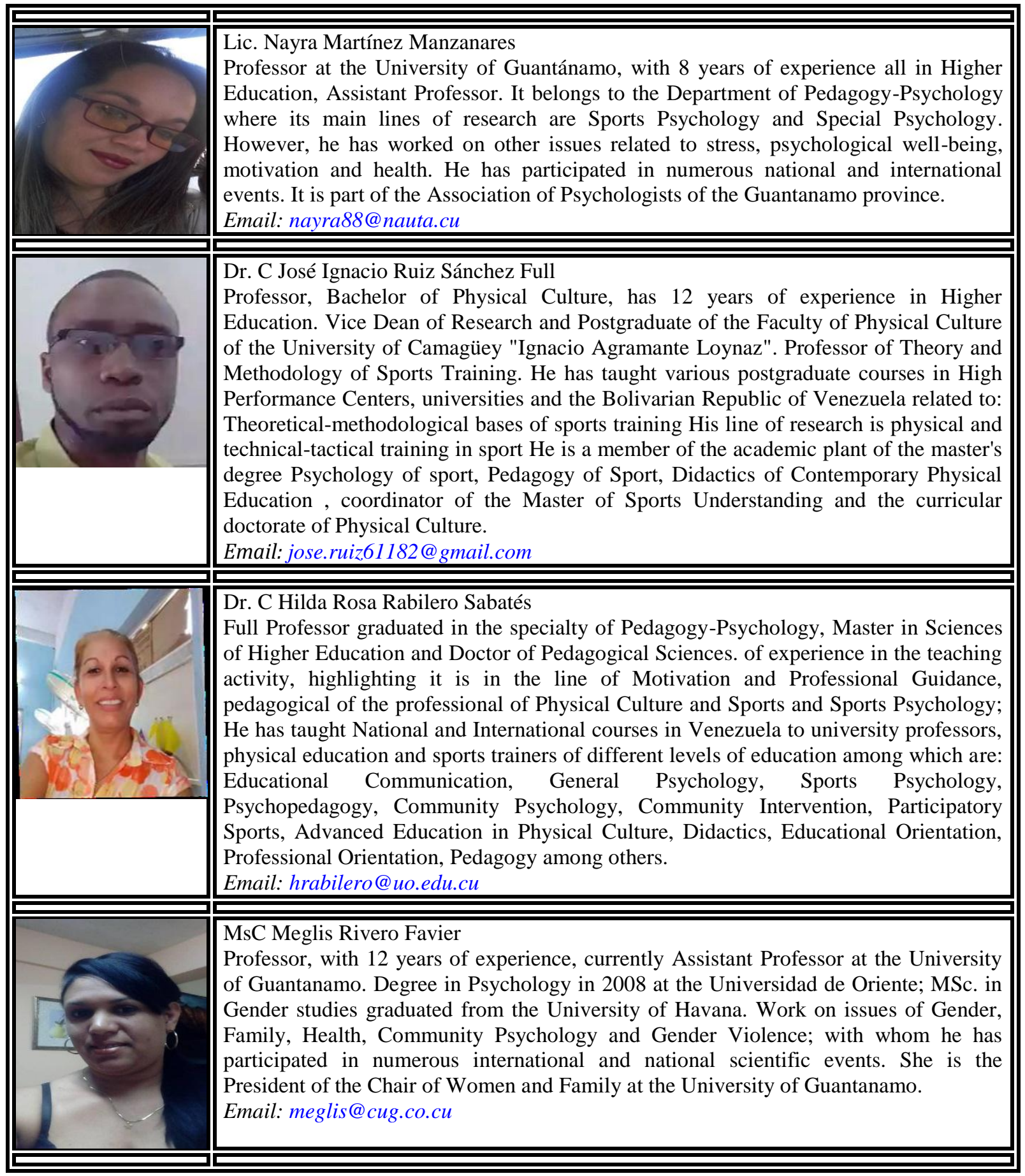

Manzanares, N. M., Sánchez, J. I. R., Sabatés, H. R. R., \& Favier, M. R. (2020). Educational strategy to favor the satisfaction of basic psychological needs in young people of yogic group studies Al Ananda De Guantanamo. International Research Journal of Engineering, IT \& Scientific Research, 6(2), 7-13. https://doi.org/10.21744/irjeis.v6n2.857 